\title{
Conceptualizing Humanistic Competence in the Language Classroom by TJP - A Chinese Case
}

\author{
Ling Zhang (Corresponding author) \\ Hunan University of Humanities, Science and Technology, China \\ E-mail: 1zha6628@gmail.com
}

Chris Atkin

Faculty of Education, Liverpool Hope University

Hope Park, Liverpool, L16 9JD

Tel: 44-0151-291-3801Ｅ-mail:atkinc@hope.ac.uk

\begin{abstract}
As learning is seen to be a social process as well as an intellectual activity in which teachers work in active partnership with students, "Teaching by Joint Presentation" (TJP) project sought to investigate what a humanistic concept of teacher-student joint presentation and critical inquiry can evoke in the language classroom within Chinese context. 289 college English literature learning students and 87 in-service secondary school teachers have participated in this study. The findings articulated a series of multifaceted differences concerning with students' learning aspiration and competence, together with the complexities of teaching methods in a humanistic language classroom. The results indicate that humanistic ideal does increase students' learning competence of critical insight, independent thought and reflective analysis. The study provides insights into humanistic competence growth of Chinese college language students based on empirical evidence.
\end{abstract}

Keywords: Humanistic Competence, Joint Presentation, Critical Inquiry

\section{Introduction}

It is generally acknowledged that the commonest solution to language teaching problems lies in the adoption of new teaching methods. Teaching by Joint Presentation (TJP) is one of the methods performed by a group of English literature teachers in a university in Hunan Province, China. It is implemented by obliging the participants to co-present and co-inquire the teaching contents by joint presentations from both the teacher and students in the English literature course. Resources of the presentations come either from the library books and journal articles or from the internet collected by the students themselves. TJP project suggests that the experiential and cultural contexts of both the teacher and student could be identified and integrated into the classroom. It also assumes that the intentional and purposeful designed student's participation of classroom presentation and critical inquiry would enhance their self-directed learning autonomy and independent thinking competence.

Featured by self-directed learning that needs and contributions from students are highly valued, TJP project starts from the basic assumption that there is an interpretation gap between the teacher and student towards the same topic. Traditionally this gap is often separated from each other. Instead of devaluing the existing didactic method, TJP project recognizes the fact of its remaining authority and attempts to integrate with it. TJP assumes that to conceptualize a humanistic classroom demands a compatible contribution from both innovation and convention, or from both teacher and student.

The target groups identified in this project include 289 college English literature learning students, and 87 secondary school teachers who are receiving their in-service professional training on weekends or holidays. Its aim is to activate students' humanistic participation of critical thinking and self-directed learning in class. There are two purposes for this study: the first is to present findings to prove that humanistic concept does make differences concerning with students' learning aspiration and competence. This will provide a case study that has intentionally tried to explore a diversified method to make the participants learn by doing and thinking. The second is to raise some reflections that have emerged from this study relating to the complexities of teaching methods in a humanistic language classroom.

One of the research questions for the TJP project is: What are the commonest prevailing teaching methods applied by teachers at the tertiary level in China? Responses from the target student group of the TJP survey "What's your impression on your teacher's organization in the classroom?" tend to describe as: preparing their 
lessons well, illustrating explicitly, trying best to convey what is needed to instruct by demonstrating certain contents beyond the textbooks, exploiting some power to attract the student's attention to prevent them from being bored and so on. This can be inferred that their understanding of teaching is that the teacher takes all the responsibilities and dominates the classroom by presenting. The students are familiar with this top-down method. Teaching seems something none of their business. Additionally, the replies from the in-service teacher group are like this: attempting to illustrate as much as possible; leading the students exhaustedly to meet the criteria of those stressful tests from the administrative organizations; playing the roles of director, designer, organizer, presenter, assessor, and resource in the classroom etc. This implies not only a teacher-centred classroom, but also a sense of being a toiled teacher. Possibly there are more, for example, the hint of inquiry - is what is taught indeed learned?

\section{Literature Review}

The literature framework that TJP project adopted has drawn heavily on the concept of humanistic psychology with self-directed learning and critical thinking.

By self-directed learning, it refers to the development in student of powers of critical insight, independent thought and reflective analysis. Its characteristics evoke associations with a cluster of distinct phenomena: personal autonomy, the ability to manage one's own learning, a teaching and learning environment which encourages learner participation, the independent pursuit of learning outside formal institutions, the social exploration of interconnectedness and collaboration, the awareness of self reconstitution under the embedded cultural context and so on (Tennant, 1998; Brookfield, 1993). Tennant (1998) points out that the concern with the self is a hallmark humanistic psychology, which reaffirms the human qualities of the person, such as, personal freedom and the validity of subjective experience, or the quality of self-actualisation.

As to critical thinking, Richards et al defines it as "a level of reading comprehension or discussion skills when the learner is able to question and evaluate what is read or heard" (2005:174). This implicates that in learning the students are actively engaged in a deeper processing. Respect should be paid to students as independent thinkers who are proficient at particular mental processes, such as analysing, inferring, synthesising and evaluating. Critical thinking specifies cognitive skills and the mental processes involved in different aspects of thinking, naming clarifying, judging the basis for a decision, inferring, making suppositions, verbal reasoning, argument analyzing and so on (Ennis, 1985, 1998).

From the humanistic process perspective, Rogers $(1961,1983)$ advocates a student-centred approach. He emphasizes relevance, participation, negotiation, self- assessment, the centrality of the self-actualizing potential, and the scope for personal expression and creativity in meeting individual learning needs. The basic tenets determined in the humanistic learning process are that much significant learning is acquired by doing and learning is facilitated when the student participates responsibly in the learning process.

In the light of humanistic philosophy, McKenna (1995) argues that the objective of education is to facilitate the development of the student to achieve self- actualisation. Humanistic processes are described as a series of progressive changes which optimize the potential of the student towards the goal of inherent purposes, internal organization and infinite creativity.

From language learning aspect, Ely (1986) maintains that the variables of class participation and sociability are the possible major determinants of language proficiency. Ghaith and Diab (2008) reveal that language acquisition is determined by interaction among a number of student-related and contextual factors, and the using of humanistic method of teaching can increase students' motivation and class sociability.

These all articulate a similar point that adds weight to the central proposition advanced in this TJP study, namely that humanistic ideal does have positive influences on students' learning competence. More specifically, TJP provides Chinese students with intellectual resources that can help them to be successful academically.

\section{Design and Methods}

The TJP activities have been developed, implemented and evaluated within two groups. The aim of each group is to explore the effect of TJP activities on:

- How fast can the target student group accept the self-directed learning concept and how much can they be transformed and improved by doing presentations and ask critical questions by themselves?

- How much can the in-service teacher group be transformed by the self-directed learning concept and how well can they implement the presentations and deal with inquiries in class? What can be inferred?

The student group includes 4 classes in Grade 2 and 4 classes in Grade 3 of a university in Hunan. The in-service 
teacher group incorporates 3 strands of English language teachers in 3 different prefectures of Hunan Province. In addition, there are 4 matched classes in each grade that no TJP activities have been carried out; these classes have served as comparison strand for the purposes of evaluating the effects of the project. Unfortunately, no control group was found for the in-service teacher group for comparison. Instead, a qualitative interview with some of the in-service teachers was conducted to collect the data for the study.

Each target student is scheduled to demonstrate a group presentation or an individual presentation with the same topic as their teacher does in class. The target presenters should exhibit a different interpretation or some complementary elements based on the teacher's teaching materials that are provided one month in advance. Following each presentation, three critical questions are to be put forward by the rest of the listeners. The target presenters should hold on their grounds by contending. At the end of each semester, the presentations and critical inquiry of the target students will take $20 \%$ of the final exam scores. A test with $35 \%$ of marks will go to examine the student's independent and critical insights into any of the issues they chose to describe about literature. Then a comparison between the target students and the control groups was conducted within the score of $35 \%$.

In the meanwhile, each of the in-service English teachers is required to demonstrate a lesson exploiting learner-centred conception to organize the class. $65 \%-75 \%$ of their class time is demanded to be occupied by the students. Comments and suggestions on each target teacher's performance are given after their lessons. Several websites are provided to these target teachers. Its aim is to help promote the self-directed teaching strategies and search for their teaching contents. During the one-year training program, each target teacher should deliver at least three lessons. Both groups are assigned some teachers from TJP project to coordinate with their submission of presentation materials, their inquiries and the feedback from the study. The impact of the project is being evaluated by a range of methods. These include:

- Quantitative data collected by questionnaires and a standardised test of attainment after each semester of learning.

- Qualitative study of several target participants based on interviews and email communications.

- Qualitative data collected through action research and observation of the participant's presentations.

\section{Findings and Emerging Issues}

Although all participants have attended the TJP project, the findings from the two groups are different.

\section{Positive findings from the target students group}

General findings from the TJP project support the aim - humanistic ideal does make differences concerning with students' learning aspiration and competence. This can be seen from some remarks quoted from the target students through emails and questionnaires.

- Free students' mind: Following the analysis of the collected questionnaire data,

more than $90 \%$ of the participants believed that TJP made them realize learning from only books and teachers was not sufficient. Here are some quotes from the students: "Learning from life and peers has broadened my view of understanding", "To be out of the classroom, I genuinely found what should be learned. I now know what to invest my time and effort". Another interesting finding from the data was that, via the TJP training of critical inquiry about the presentations, some students formed a habit of seeking for curiosities in life: "In the process of looking for answers to the curiosities, I found some interests for my future career".

- Promote thinking skills: TJP project offered sound evidence of broad and narrow thinking skills which could be developed by means of teaching practice. Around $45 \%$ of the target students acknowledged that after two years of attending the TJP model classes, they were more aware of forming reasoning and making judgement. $66 \%$ showed that their learning were more consciously goal-directed. A very interesting finding of the TJP model was that some students who seem quiet in classrooms were actually active observers and listeners with many typical thoughts of their own.

- Enhance learning strategies: "I improved my learning strategies by surfing on the internet and gathering materials via collaborative team work", "Organizing information to develop stronger schema, monitoring mistakes, controlling anxieties, and asking questions to get verification helped me formulate my learning styles". This assured that TJP with a deliberately creative variety to the students could evolve a range of stylistic and strategic preferences: "University study means to equip yourself with strategies that helps change your life even as time changes". It also enhances their learning autonomy.

- Improve communicative competence and confidence: TJP and critical inquiries created more speaking chances 
for the target students. While in the learning process of responding to a question, the students had to try their best to say rather than to read; their attention was concentrated on holding their grounds and forgot the anxiety. Their learning confidence was spontaneously improved as they gained more fluency from their oral experiences: "My communicative competence has stimulated while searching, cooperating, and sharing in completing the tasks in TJP project", "I never realized that I could, but TJP project pushed me to reach that". A common summary of their weakness for performing the TJP tasks went like: "We prepared more but found less time", "More practices should be conducted before delivering the presentations in class".

- Develop self-awareness of responsibilities: Feedback from the target students revealed that TJP approach could be used to encourage self learning responsibility. The permeated ideas raised from the target students were "to enter a university does not actually mean to take some knowledge out unless you take some responsibility", or "to study in a university does not mean to fulfil the parents' ambition but your own". TJP project urged the target students to be involved in the organization of learning process. They had to learn to cope with their new roles. Hence the responsibility for learning was potentially passed to them. This fitted the aim of TJP that was to make the classroom a democratic and negotiated place. The students should dominate the class as a talking head, a creative body, and a self-managed learner. A typical comment on TJP by interviewing was something like: "I would never have realized that the participation of this project supplied me with a sense of adulthood, I'm the decision-maker of my own learning."

\section{Problems from the target students group}

Complaints and negative attitudes collected from the TJP project implied that there were still a lot more needing to synthesize for the research. The trial outcome of TJP project went beyond a merely technical application, but a much broader, complex and contested notion.

- Didactic learning versus reflective learning: It is acknowledged that the Chinese students are more used to the didactic learning methods. This exerts considerable pressure upon the TJP reflective method. Findings from observations in class showed, although all the target students joined in the TJP tasks, most of them still longed to hear the voices from the teachers - either for the comments on their presentations or for the summaries of the inquiries. More than half of the target students described that they concentrated more on the teachers' lectures than on the students' presentations and inquiries. Here are some quotations: "To learn by doing was great fun, but too hard for me", "I'm quite happy with my present learning approach. Why bother changing?"

- Self-navigation versus teacher support: The need to individualised instruction was a subsequent appeal from the target students in TJP project. Self-navigation with more flexibility on the students' side was often determined by their responses to different situations and tasks. This could be misled by their uncertainty, disorder and ambiguity. Replies from the target students uncovered the weaknesses of self-directed TJP preparation: "I tried my best but still in vain to reach the minimal anticipation of my peers, I hope to go back to be with my teacher as an authority", "We rush into action without sufficient preparation". Technique and strategy oriented teacher support was eagerly demanded from the target students. It was summarized from the TJP projectors that a supportive network for TJP should be established: "I found it hard to express my opinions appropriately while being promptly asked".

- The availability of the computers with internet was another problem. Complaints from the students indicated: "Those computers were awfully slow, it took me too much time preparing the presentation materials", "I found it was hard for me to get a computer desk on campus. I had to go to those net bars with terrible working conditions".

In summary compared with the controlled students, the target students seem soundly developed in stylistic flexibility. Their range of competence after the two- year TJP project is extended: more open-minded and optimistic about anything new and less likely to resist change, more thoughtful of probing questions, and more eager to test things outside class. It indicates that TJP project is an effective learning method within the Chinese context. It integrates the model of student navigation and teacher support with didactic and experiential approaches complementing each other. This can increase the overall engagement of students and to make better use of their creative potentials.

\section{Issues emerging from the in-service teachers group}

Interview feedbacks from the in-service teachers seemed more concerned with the application of TJP concept rather than the model itself. It was obvious that they were lacking of confidence to adopt the humanistic TJP method within their contexts. As for themselves to change the views of teaching, those younger teachers accepted and practiced much faster. Whereas, the middle aged found it too challenging to follow. They thought it 
too hard to control the self-directed classrooms while the teachers lost their authority. One of the conspicuous facts was that all these in-service teachers thought of teaching as a torture of meeting the examination goals from the administrative stakeholder. Their general consensus towards learning was "no pain, no gain", thus teaching by amplifying more learning points in class and assigning piles of homework became their common instrument.

- More consideration at self-reflective situations: Contrasted with the target students group, the in-service group tended to look inward themselves and their teaching situations. "TJP program did provide us with some fresh professional concepts, but had no relationship with the quality of our teaching". This disclosed their inner dilemma - to change or to tolerate. To change meant that they would implement the TJP or other innovative teaching methods. They had to consider the students' involvement to a proper degree, their own frequent self-update, and the responsibility for the undesired learning outcomes. These seemed hard job, and they might risk facing misunderstandings from parents, colleagues, administrators and stakeholders. Yet choosing to tolerate meant to follow the existing stereotypes, to be exhausted as the sole source of power. Most in-service teachers expressed that personally they did hope to use TJP method and try the humanistic conception of teaching. However, they could not avoid finishing those teaching tasks assigned by schools. How to help their students to meet all those examinations criteria were their reality of teaching. "There would be tensions between the existing stereotypes and the TJP model". Thus transformation and reality often conflicted in their teaching. The improvement of teaching methods alone was not sufficient as a basis for educational reform. Learning contexts, which functions as a focal point, could never be ignored.

- Multilevel class: As the in-service teachers were coming from 3 prefectures in Hunan, the class was always characterized by heterogeneity: their English language level varied from the advanced to beginners. Some were sent to teach English because English teachers were not enough in their community. Their ages stretched from the twenties to the fifties, and the locations of their coming schools diversified with rural, urban, or suburban areas. Their teaching concepts and resources were of significant difference, and their goals and reasons for taking an in-service training were of great variability. Therefore, the only model of TJP method seemed too exclusive to satisfy the anticipation from all the teachers. Interview data revealed several facts about the in-service strand: those younger and urban English teachers shifted and enhanced quickly. "TJP project developed both our personal and professional qualifications for teaching". While those elder and rural ones seemed a bit reluctant to change. Those who attended the training program just for the goal of securing their teaching positions treated TJP a great burden of bother. "I guess the responses from the rest of the faculty members would be negative and resisted". Also, not all the teachers took their training as their tasks, salary raise was their aim of taking an in-service program. Thus the consequences from the TJP in-service strand experiment demonstrated that keeping up to date with teaching and learning ideals was considerably more complex than we previously might have thought.

- Network mediated collaboration: Although the application of TJP in class was doubted by the in-service teacher group, TJP ideal of learning by collaboration, negotiation and sharing was broadly recognized as lifelong necessity. Therefore, a network mediated group was set up during the training with varieties of information and websites by the in-service group. All the digital resources of their teaching presentations were uploaded. Their inquiries received feedbacks both from their teachers and peers. A relationship of peer coaching and mentoring had formulated. Some even recruited their students to join in the network and initiated a flexible online joint learning platform. Emails had become a common communication tool for receiving resources, submitting assignments and fulfilling cross-school works. IT helped create a platform to keep everyone in touch for the integration of self-directed and cooperative learning.

- A constructive view of testing: Traditional paper testing was not the only measure for grading in TJP project, presentations and critical inquiry were vital elements for evaluating the students. Testing became a combination of opportunities, partially seen as an interaction between teacher and student, and partially judged by the knowledge the students had. The $20 \%$ of scores for presentations and critical inquiry as well as the $35 \%$ of scores for critical comments in the written test intended to stimulate the students to improve their all-round learning and skills. Around $80 \%$ of the target students group said that it was the scoring comments returned promptly from the teacher and their peers that made them reflect their teaching. And they could be aware of their strengths and weaknesses timely. TJP test additionally set an operational example for the in-service teacher group to reconsider the right components they should cover in their testing design. Of course, there were some problems from the TJP in-service teacher group. That was, although general language teaching presentations were easy for them to deal with, teaching with TJP humanistic and collaborative concepts seemed less fully manageable. Some of them felt ambiguous about their roles in class, and some still could not psychologically shift from an authorized position: "To learn by doing or to teach by sharing is still a big problem for some of the teachers to tackle in an appropriate way". Computer-assisted assessment was almost impossible because of the lacking of sufficient 
facilities and because of the teachers' lower computer operating ability.

- Teaching means lifelong learning: Completing a research project was only the beginning of a lifelong quest to better understand our students and the approaches we used for teaching and learning. Only when continuing education was ensured could new ideas be stimulated and old practices be reconsidered. The voices aired by most of the in-service teachers at the end of the TJP training program were: "TJP project at least caused my curiosity to seek for future professional rewarding." "Teaching with various participations is, in itself, continual experience enrichment, since one really learns when asked to elaborate and explain critically." "Actually challenges have already encountered, we merely pretend not to see it." Therefore, while TJP project improved the college students' aspiration and competence in learning, it increased more availability of teaching concepts for the educational practitioners. It developed an ongoing, sustainable, and constructive lifelong learning setting among the intellects.

\section{Reflections and Implications}

Society is a complex system in a state of continuous change. This has made human learning firstly a lifelong experience. One has to keep learning in order not to be excluded. Secondly a humanistic process, individuals are not merely the passive recipients who can also act back upon their world and become agents contributing to the process of social change (Javis, 2002). TJP is a project based on this humanistic concept albeit with complex outcomes.

- The most important factor in language learning is still memory: Evidences from both groups reveal that the most popular way of language learning in China is still memorizing, even though it is designed in a humanistic way. It is memory that enables the TJP participants to recall knowledge and to perform their presentation skills. Most of the target students tried to recite their presentation materials rather than to perform. Even for the in-service teachers to deliver a lesson, they also attempted to recite some key points and sentences. The TJP practitioners have observed that those highly regarded quick learners or experienced teachers at the beginning of their presentations still struggled with one form of memory or another. Analysis to this phenomenon from the TJP projectors have been attributed to three aspects of reasons: One is because of the Chinese learning tradition people are used to the traditional listening- memorizing methods. Listening carefully and concentrating on what the teacher presents, taking notes and memorizing are still the right stereotype of hard-working students. The second might be the meaning. While in one interview with an in-service teacher, she told that she had to recite when she did not have a clear sense of the meaning of what she presented. Since most of the TJP participants collecting their presentation materials from the websites, they found it hard to fully understand the meaning. The next reason is language usage - using what has been learned in real situations seems always difficult. Cultural contexts, professional registers and pragmatic conventions are always the elements that prevent the TJP participants from appropriately expressing themselves.

- Teaching methods are complex exploration: It is concluded by the TJP projectors that teacher-flexibility is crucial in a humanistic class. Teachers need to be trusted to employ a range of methods and work almost "independent of methods" (Richards, 1990). Free decision of teaching methods can be handled over to the teachers if learners are encouraged to develop their own learning strategies. For example, critical inquiry in TJP project has made the students become aware of how effective they can learn in an ideal process of much more reflective and self-directed teaching contexts. It builds up the students' confidence in a learning environment of being understood. Meanwhile, it also shows that the students demanded more power to decide their own learning individualities in class. The teacher's traditional prescriptive status should be complemented by more open methods collaboratively. Data from the in-service teachers group in the meanwhile discover that even if in the same grade with the same teaching materials, teaching methods and paces are not the same with different classes. In fact, the outcomes of TJP project reflect that teaching methods under the advocate of transformation seem a paradox context. On the one hand, students are encouraged to express how they want to be taught, to take part in the teaching, and to be dependent in their own efforts; on the other hand, obligatory exams coming from the comparatively conservative administration side are to be followed. This makes the project a complex to run.

- Top-down teaching method is inevitable: Despite the rhetoric, TJP project projectors insist that continuous and sustainable teaching method innovations should be inevitably top-down. TJP project findings from the target student group display that many students are likely to have less intellectual interest in the language than an excellent teacher. As for the in-service teacher group, although all of them admit that innovations in teaching are necessary, they do not agree to change on the basis of logic alone. They often feel threatened by theories coming from experts. Also, many innovation projects imply a threat to the teacher's professional status.

- Experiment in seeking for one's own approaches makes sense: In spite of the fact that teachers appear to be eclectic with the ongoing top-down professional orientations, their attempt to developing their own sets of 
approaches makes more sense. This can not only accommodate the new top-down theories to fit in with teachers existing beliefs, but also can drive teachers to adapt their own approaches according to their contexts and the impact of professional development. The outcomes from TJP project have at least provided two dimensions of positive factors to support this. The first dimension is that students' learning individualities and strategies are often from interaction with their own experiences. Teacher's guidance and obligation only function as their starting point and impetus for persistence. The second dimension holds that there are many similarities among all teachers in approaches that guided their pedagogic practices, regardless of their teaching situations. However, initiations of teachers' classroom-oriented method of practice do cater more effective for the students' needs and anticipations. At least, it offers different scenarios to make students' view broadened.

- More research on assessment techniques is urgent: In spite of the great efforts devoted to teaching methods innovation, testing has unfortunately been regarded as an exclusive grading of students' learning achievements. It has been sometimes viewed by teachers and students as unfair measures of learning competence. Feedback from the in-service teachers group indicates that one of the most important reasons for teachers reluctant to initiate new teaching methods is that they have to meet the requirements of the testing systems set up by administrators. These tests focus on examining the essential memorizing knowledge based on students' textbooks. Meanwhile, many target students returned to the traditional learning way after the TJP experiment only for passing the examinations. Although innovations in teaching and learning have gradually been common practices, the testing system remains almost the same. This has often led to great conflict. Thus explorations on innovative teaching and learning methods together with a matching testing system are of crucial significance.

\section{Conclusion}

TJP project sought to conceptualise what a humanistic method of teacher-student joint presentation and critical inquiry can evoke in a language classroom among college students and in-service schoolteachers in the Chinese context. In spite of the acknowledgement that teaching methods exploration are a complex problem, outcomes of TJP project have generally turned out to ensure that humanistic ideal does make positive influences on students' learning competence of critical insight, independent thought and reflective analysis. And contributions to initiating new teaching methods do make sense on continuing professional development. Through empirical studies, TJP also deploys evidence from the in-service group interviews that the wish to change teaching methods often comes from the outside. This does not meet the needs and concerns of the teachers and the circumstances in which they work. Hence, in language learning class there will be no one method that is right for all, especially with a humanistic conceptual context. It is anticipated that the findings of this minor attempt can amplify the educational exploration for models of language teaching and learning. And the TJP study can provide insights into the humanistic competence growth of Chinese college language students.

\section{References}

BROOKFIELD, Stephen. (1993). Self-directed learning, political clarity, and the critical practice of adult education. Adult Education Quarterly. 43/4, 227-42.

ENNIS, Robert H. (1985). A logical basis for measuring critical thinking skills. Educational Leadership. 43/2, 44-48.

ENNIS, Robert H. (1998). Is critical thinking culturally biased? Teaching Philosophy. 21/1, 15-33.

ELY, Christopher M. (1986). An analysis of discomfort, risk-taking, sociability, and motivation in the L2 classroom. Language Learning. 36/1, 1-25.

GHAITH, Ghazi \& DIAB, Hassan. (2008). Determinants of EFL achievement among Arab college-bound learners. Education, Business and Society: Contemporary Middle Eastern Issues. 1/4, 278-286.

JAVIS, Peter. (2002). Adult and Continuing Education: Theory and Practice. $2^{\text {nd }}$ ed. London: Routledge.

McKENNA G. (1995). Learning theories made easy: humanism. Nursing Standard. 2/9, 29-31.

RICHARDS, Jack, C. (1990). Beyond methods. In RICHARDS, Jack C. (ed) The Language Teaching Matrix. Cambridge: Cambridge University Press.

RICHARDS, Jack C, SCHMIDT, Richard, KENDRICK, Heidi. \& KIM, Youngkyu. (2005). Longman Dictionary of Language Teaching and Applied Linguistics. Beijing: Foreign Language Teaching and Research Press.

ROGERS, Carl R. (1961). On Becoming a Person. Boston: Houghton Mifflin.

ROGERS, Carl R. (1983). Freedom to Learn in the Eighties. Columbus: C. E. Merrill Pub. Co.

TENNANT, Mark. (1998). Psychology and Adult Learning. New York: Rourledge. 